\title{
Bilateral developmental dysplasia of the hips
}

While training as a surgeon, Sophie West was diagnosed with bilateral developmental dysplasia. This is an account of her experience of the condition and of becoming a patient

\author{
Sophie West patient ${ }^{1}$, Johan Witt consultant orthopaedic surgeon ${ }^{2}$ \\ ${ }^{1}$ London Deanery School of Surgery, London UK; ${ }^{2}$ Orthopaedics and Trauma Service, UCH Referrals Centre, University College London Hospitals, \\ London, UK
}

This is one of a series of occasional articles by patients about their experiences that offer lessons to doctors. The $B M J$ welcomes contributions to the series. Please contact Peter Lapsley (plapsley@ bmj.com) for guidance.

\section{Something wrong}

I had just been offered a place on the London Deanery core surgical training programme, and was half way through completing my master's degree in sports and exercise medicine. I was also training for my first triathlon, having completed a duathlon the previous year. One night I woke up with groin pain. After checking myself repeatedly for hernias, I took some painkillers and managed to get back to sleep. The next morning I could hardly walk due to pain in my left hip and so hobbled around for the next couple of days, after which the pain improved and disappeared. I assumed I had pulled a muscle or something. I thought nothing more of it until it happened again about two weeks later, and then again, and again. After the fourth time I realised that something was not right and I got some radiographs done. A professor on my course reviewed the films and immediately told me I had hip dysplasia.

Despite having worked in orthopaedics during my second year as a junior doctor, I thought this condition was only seen in babies; my only experience had been when I performed the Ortolani and Barlow tests as part of new baby checks as a medical student. If it is missed in childhood, problems can develop later in life, but I still struggled to get my head round the fact I had this condition that was going to significantly affect my ability to walk. From the outset an osteotomy was mentioned, and I adamantly stated that no-one was going to break my bones, let alone my pelvis ... this was real denial!

\section{Accepting the diagnosis and treatment}

One of the benefits of working in the NHS was that I was able to bypass the usual referral routes and had access to several opinions from orthopaedic specialists. After the fourth surgeon had told me I needed a periacetabular osteotomy on my left hip - a surgical procedure in which the bones of the hip joint are cut, reorientated, and fixed in a new position-it started to dawn on me that this was the path I was going to have to take. During these months the pain had become a permanent feature and my right hip had also started to hurt, meaning that my mobility was becoming progressively impaired. In just a few months I had gone from running 20 kilometres a week to relying on crutches to walk and being in pain most of the time. The irony of the orthopaedic senior house officer being on crutches did not escape my patients either.

Knowing now that I was going to need two lots of major surgery, each with prolonged recovery and rehabilitation periods, and potentially lifelong problems with my hips, left me in a state of despair. I felt that my life was turning upside down. By this time I had started working at the hospital where I was going to be treated, and despite having lots of colleagues to talk to about the condition and the operations, no one could tell me what it was like to have a pelvic osteotomy and how it was going to affect my life-I felt very alone.

\section{Finding support}

I discovered a charity, Steps, of which I have since become a trustee. Through their family contacts, they put me in touch with other people with developmental dysplasia of the hips. It was such a relief to be able to talk at last to someone who understood exactly how scared I was, what it was like living in pain, and who could answer some of my questions about surgery and recovery. One of the things that struck me talking to fellow patients was the length of time and number of visits to different specialists many people had been through to get an accurate diagnosis. Although this did not surprise me (having not known about it myself) it highlighted for me the importance of recognising the causes of hip pain in young adults. 


\section{Being a patient}

Most people are apprehensive about being patients, but as a surgical trainee I had insight into what I was really letting myself in for, especially when I ended up having to assist my surgeon doing the operation on someone else. A periacetabular osteotomy involves the bones around the hip socket being broken and then realigned to give better coverage of the femoral head, restoring the biomechanics of the joint to nearly normal in the process, and reducing the risk of secondary arthritis-joint preservation surgery. I was relieved to have this option available to me; the thought of a total hip replacement at the age of 27 years was a frightening prospect, and until recently that was the only option available to people in my situation.

I am lucky; I have a supportive husband and family. We quickly realised that this was something we were all going to go through together. After the operations I was not going to be able to look after myself, which meant moving out of the flat I share with my husband and staying with my parents over 70 miles away. After each operation I was unable to put any weight through my hip for six weeks and then I gradually built up to walking with no crutches over the subsequent four weeks. I also used a wheelchair to go out of the house as it was too tiring and painful to walk with crutches all the time. The hardest thing was after the first periacetabular osteotomy, knowing that however much pain I was in, I was going to have to go through it all again with the right hip.

I felt extremely vulnerable as a patient, and the complete loss of independence was something I could not have prepared for. Relying on others to help you complete the most basic of daily tasks (washing, dressing), initially from colleagues at work and then from my husband and parents, was a revelation to say the least, and it has given me insight into being a patient that I could never have appreciated before. It was an eye opening experience using a wheelchair, seeing how differently people treat you, and just how hard getting around in one can be.

\section{Bridging the gap}

Most orthopaedic surgeons carry out thousands of procedures in their career, while very few will need one of these procedures done themselves. I wanted to be able to use my experience to bridge this gap of knowledge. Along with my surgeon, we arranged a focus group including anaesthetists, pre-assessment nurses, physiotherapists, and occupational therapists. We invited five patients who had undergone a periacetabular osteotomy, including myself, to share their ideas, concerns, and experiences. The most interesting outcome was the difference between what the medical team thought would be the most discussed topics (such as pain and hospital stay), and what the patients actually felt were the most important factors (such as information before and after the operation and the rehabilitation period). This experience has shown me that as physicians, while we think we know how patients may feel and what they are worried about, we really don't. The experience of the focus group was valued by everyone involved and has led to changes and better provision of information for patients. A patient focus group with a multi-disciplinary team input is an excellent way to understand our patients and the conditions we treat.

\section{Looking forward}

Although I still have one small operation on my right hip to come, I am now getting on with my life with the knowledge that my hips still have plenty of years left in them. I am enjoying working and finally getting on with my training, and have even entered a triathlon for next year. It will be three years since I last signed up to one, but I know the achievement now is going to be so much greater.

Competing interests: All authors have completed the Unified Competing Interest form at www.icmje.org/coi_disclosure.pdf (available on request from the corresponding author) and declare: no support from any organisation for the submitted work; no financial relationships with any organisations that might have an interest in the submitted work in the previous three years; no other relationships or activities that could appear to have influenced the submitted work.

Provenance and peer-review: Not commissioned, not externally peer-reviewed.

Accepted: 12 January 2011

Cite this as: $B M J 2011 ; 342: \mathrm{d} 2152$ 


\section{A doctor's perspective}

Hip dysplasia is a condition in which the acetabulum is too shallow and does not effectively cover enough of the femoral head. About $80 \%$ of cases occur in female patients. The consequence is that weight bearing stress is concentrated over a small area of the articular surface, and this initially causes damage at the junction of the acetabular labrum (the ring of cartilage that surrounds the acetabulum) with the articular cartilage. If this abnormal stress continues in this area, it can result in the breakdown of the articular cartilage and in turn osteoarthritis.

Hip dysplasia is a common cause of osteoarthritis of the hip in patients aged between 50 and 80 years. About $80 \%$ of patients coming in for hip replacement surgery have a biomechanical abnormality of the hip, which leads to the development of osteoarthritis; in women, the commonest abnormality is hip dysplasia. This trend in women suggests that earlier in life a lot of these patients may well have had unrecognised symptoms. Hip symptoms caused by dysplasia commonly present as pain in the groin region that are associated with activity. For example, symptoms may initially begin after a sporting activity, but as damage to the labrum progresses, pain becomes more persistent and can be very severe, sometimes necessitating the use of crutches.

The diagnosis of this condition relies largely on the awareness that recurrent groin pain associated with activity in a young individual is not normal and requires further investigation. The diagnosis can usually be made with plain radiographs, but these require correct interpretation - for example, subtle dysplasia where the deficiency is largely anterior can easily be missed by a radiograph. MRI scans by themselves can be misleading, in that labral tears are very common in the presence of dysplasia because this is where the initial lesion develops. Although this may be diagnosed on MRI, dysplasia leading to the tear will not necessarily be recognised.

Once patients show symptoms, this is an indication that the hip is starting to decompensate with damage occurring at the capsulo-labral complex. Treatment is largely based around correcting the underlying structural abnormality of the hip. This type of surgery is suitable for patients in whom the femoral head is not too deformed and where arthritic damage has not progressed too far, hence the importance of early recognition.

Periacetabular osteotomy is the procedure of choice to correct the bony abnormality. The surgery involves rotating the acetabulum into a new position after making bony cuts to free it from the pelvis. The acetabular fragment is then held in the new position by screws. This allows the patient to mobilise and start rehabilitation without the need for external splints. For the patient, the idea of such a procedure can be quite daunting because it is clearly a major intervention. An advantage of increased subspecialisation in surgery is that procedures such as this can now be performed safely and effectively with good reproducibility in terms of outcome. This type of surgery can also be performed through a small, cosmetically acceptable incision $(8-10 \mathrm{~cm})$, which is an important consideration for young patients.

Recovery after surgery is related to psychological factors surrounding the procedure itself and patients' perception of how they will be during and after surgery. Identifying these factors before surgery is extremely important so that they can be addressed. We have found that a patient focus group has been very helpful in identifying factors that can clearly influence recovery.

Johan Witt jdwitt@doctors.org.uk

\section{Further reading}

Steps charity (www.steps-charity.org.uk)—National UK based charity that provides support and information for patients and their families with lower limb conditions, including developmental dysplasia of the hips. "We don't take walking for granted".

The International Hip Dysplasia Institute (www.hipdysplasia.org) - International group with the mission to reduce the physical, social, and economic burden for children and adults affected by neonatal hip instability and hip dysplasia. They provide information for patients and medical professionals and conduct important research into the condition.

Hip Surgery (www.hipjointsurgery.co.uk) —Website providing information on hip dysplasia, hip arthroscopy, femoralacetabular impingement, periacetabular osteotomy, and total hip replacement. Developed by Johan Witt (co-author of this article), an orthopaedic surgeon specialising in hip conditions in young people. 